\title{
Strategies in the processing and analysis of continuous gravity record in active volcanic areas: the case of Mt. Vesuvius
}

\author{
Umberto Riccardi $\left({ }^{1}\right)$, Giovanna Berrino $\left({ }^{2}\right)$, Gennaro Corrado $\left({ }^{1}\right)$ and Jacques Hinderer $\left(^{3}\right)$ \\ (') Dipartimento di Scienze della Terra, Università degli Studi di Napoli «Federico II», Napoli, Italy \\ ${ }^{2}{ }^{2}$ Istituto Nazionale di Geofisica e Vulcanologia, Osservatorio Vesuviano, Napoli, Italy \\ $\left(^{3}\right)$ Ecole et Observatoire des Sciences de la Terre (EOST), Institut de Physique du Globe de Strasbourg, \\ Université Louis Pasteur (UMR 7516 CNRS-ULP), Strasbourg (France)
}

\begin{abstract}
This research is intended to describe new strategies in the processing and analysis of continuous gravity records collected in active volcanic areas and to assess how permanent gravity stations can improve the geophysical monitoring of a volcano. The experience of 15 years in continuous gravity monitoring on Mt. Vesuvius is discussed. Several geodynamic phenomena can produce temporal gravity changes. An eruption, for instance, is associated with the ascent of magma producing changes in the density distribution at depth, and leading to ground deformation and gravity changes The amplitude of such gravity variations is often quite small, in the order of $10-10^{2} \mathrm{nms}^{-2}$, so their detection requires high quality data and a rigorous procedure to isolate from the records those weak gravity signals coming from different sources. Ideally we need gravity signals free of all effects which are not of volcanic origin. Therefore solid Earth tide, ocean and atmospheric loading, instrumental drift or any kind of disturbances other than due to the volcano dynamics have to be removed. The state of the art on the modelling of the solid Earth tide is reviewed. The atmospheric dynamics is one of the main sources precluding the detection of small gravity signals. The most advanced methods to reduce the atmospheric effects on gravity are presented. As the variations of the calibration factors can prevent the repeatability of high-precision measurements, new approaches to model the instrumental response of mechanical gravimeters are proposed too. Moreover, a strategy for an accurate modelling of the instrumental drift and to distinguish it from longterm gravity changes is suggested.
\end{abstract}

Key words time gravity changes - gravity record volcanic processes - air pressure admittance

\section{Introduction}

A wide set of dynamic phenomena (i.e. geodynamics, seismicity, volcanic activity) can produce temporal gravity changes, with a spec-

Mailing address: Dr. Umberto Riccardi, Dipartimento di Scienze della Terra, Università degli Studi di Napoli «Federico II», Largo S. Marcellino 10, 80138 Napoli, Italy; email: umberto.riccardi@unina.it trum varying from short $(1-10 \mathrm{~s})$ to longer (more than 1 year) periods. An impending eruption, for instance, is generally associated with the ascent of magma producing changes in the density distribution at depth, and leading to ground deformation and gravity changes observed at surface. The amplitude of such gravity variations is often quite small, on the order of $10^{-9}-10^{-8} \mathrm{~g}\left(10-10^{2} \mathrm{nms}^{-2} ; 1-10 \mu \mathrm{Gal}\right)$, so their detection requires high quality data and a rigorous procedure to split up from the records those weak gravity signals coming from different sources. What exactly would Time-Variable Gravity (TVG) tell us about mass redistribution below a volcano? The detected TVG is the sum 
of the gravitational signals originating from all geophysical sources at work at any given time. Sorting out different geophysical signals in the data is a challenge, but in principle can be facilitated by recognizing the different temporal and spatial characteristics of different geophysical phenomena (e.g., Chao, 1994).

Unlike the repeated relative gravity measurements on network, there are limited data on continuous gravity observations at active volcanoes (e.g., Imbò et al., 1965a; Davis, 1981; Vieira et al., 1991; Goodkind and Young, 1991; Berrino et al., 1997; Budetta and Carbone, 1997; Bonvalot et al., 1998; Arnoso et al., 2001, Carbone et al., 2003, 2006).

Two different approaches may be adopted to extract from the gravity records some insights related with the volcano dynamics, i.e., the analysis of the tidal gravimetric factor (delta: $\delta$ ) and the analysis of gravity residuals.

According to the recommendations of the Working Group on the Theoretical Tidal Model (SSG of the Earth Tide Commission Sec. V of the IAG), the delta factor $(\delta)$ is defined as the Earth's transfer function between the body tide signal $\left(\Delta g_{n}(r)\right)$ measured at the station by a gravimeter and the amplitude of the vertical component of the gradient of the external tidal potential $\left(V_{n}\right)$ at the station.

$$
\begin{gathered}
-\frac{r}{n} \tilde{\Delta} g_{n}(r)=\tilde{\delta}_{n} V_{n} \\
\text { where } \tilde{\delta}_{n}=1+\frac{2}{n} \tilde{h}_{n}-\frac{n+1}{n} \tilde{k}_{n}
\end{gathered}
$$

$r$ is the radius of the Earth and $\tilde{h}_{n}, \tilde{k}_{n}$, are volume Love numbers of degree $n$ (complex value), which characterize the spherical elasticity of the Earth. Thus delta factor is the ratio between the observed gravity tide and the luni-solar gravitational attraction. As it defines the Earth transfer function of the external tidal potential, the delta factor is frequency-dependent and is related to the elastic property of the Earth. Because of the viscoelastic behaviour of the Earth, its reaction to the external perturbation due to the luni-solar gravitational attraction is characterized by a certain phase shift. So the study of the tidal parameters (delta factor and phase) for the main tidal waves and eventually their time evolution could be useful to characterize the deformational behaviour in some geodynamic contexts. Several investigations (e.g., Melchior and Ducarme, 1991; Melchior, 1995; Robinson, $1989,1991)$ carried out to date show for instance that a correlation exists at «regional» scale between heat flow and the gravity tide. At very local scale Arnoso et al. (2001) suggest that the tidal response can be strongly influenced by the structure and mechanical properties of the Crust. Those anomalies are associated, respectively, with areas of thin crust, high heat flow values, and recent basaltic-type volcanic activity, and with stable structures that have a deeper Moho discontinuity and lower heat flow. Robinson $(1989,1991)$ relates the correlation found in his studies to features in the upper crust, suggesting a measurable upper crustal tidal response. Arnoso et al. (2001) obtained interesting results from the analysis of the gravity tide collected in two continuous stations in Lanzarote island (Canary islandsSpain). After a suitable reduction of the OTL effect by means of global ocean charts complemented with regional and local ones, they obtained anomalous $M_{2}$ and $O_{1}$ delta factors and phases consistent with a body tide effect. These results were interpreted as the response of a porous or cavity-filled, local, upper crust under the influence of tidal strain.

Moreover, knowledge of the specific tidal parameters for an area is required to calculate the luni-solar effect, which has to be removed from the gravity record to obtain gravity residuals.

As we are interested in modelling the transfer function between the observed gravity and the underground mass redistribution due to volcanic activity, ideally we need residual gravity signals free of all effects which are not of volcanic origin. In fact, natural (mainly body tides), man-made and instrumental sources affect the signal to noise ratio and hide the subtle volcanic signals. Therefore solid Earth tide, ocean and atmospheric loading, instrumental drift, hydrological effects or any kind of disturbances other than due to the volcano dynamics have to be modelled to be reduced in the gravity signal. The atmospheric dynamics is one of the main sources precluding the detection of 
small amplitude gravity signals. Pressure changes can reach several tens of hecto-Pascal (say $50 \mathrm{hPa}$ ) in specific locations, so the amplitude of the atmospheric contribution to gravity is as large as $200 \mathrm{nms}^{-2}$, then it could be higher than volcanic signal. This is why a large part of this paper have been devoted to illustrating the most advanced developments in that field of research and the experience of the authors is presented.

The goal of this paper is to describe new strategies in the processing and analyses of continuous gravity record collected in active volcanic areas. The experience of about 15 years at Mt. Vesuvius (Southern Italy) is reported. The time dependent behaviour of the tidal gravimetric factors is compared with the results from relative and absolute gravity surveys and seismic activity. The results are interpreted in the framework of the present-day dynamics of Mt. Vesuvius.

Mt. Vesuvius is a quiescent volcano whose last eruption occurred in March 1944. Currently, its activity consists of a low level of seismicity, sometimes increasing in numbers of quakes and energy (hereafter called seismic crises), small ground deformation, gravity changes and moderate gas emission.

\section{The Mt. Vesuvius permanent gravity station}

The Mt. Vesuvius recording gravity station (fig. 1) is located at the Osservatorio Vesuviano (fig. 1), where a recording gravity station has been operating since 1987 (Berrino et al., $1993 \mathrm{~b}$ ) and where a first experiment of continuous gravity measurements dates back to 1960 s (Imbò et al., 1964, 1965a). The permanent station is assembled on a concrete pillar located in an artificial cave, $20 \mathrm{~m}$ deep $(\varphi: 40.828 \mathrm{~N}, \lambda$ : 14.408E; $h: 608 \mathrm{~m}$ ) (Berrino et al., 1997), where the daily temperature variations are about $0.1^{\circ} \mathrm{C}$ and the annual ones are within $2^{\circ} \mathrm{C}$. The gravity sensor is the LaCoste and Romberg model D, number 126 (LR-D126), equipped with a feedback system (van Ruymbeke, 1991), with a range equivalent to $3 \cdot 10^{4}$ $\mathrm{nm} / \mathrm{s}^{2}$ (implemented at the ROB, Royal Obser-



Fig. 1. Location of the recording gravity station and gravity network on Mt. Vesuvius.

vatory of Belgium in Brussels and upgraded in 1994). The data acquisition is provided by DAS or mDAS systems developed at the ROB (van Ruymbeke et al., 1995) at a sampling rate of 1 data/min $(0.01667 \mathrm{~Hz})$. Here we focus on the results of gravity records since 1994 (fig. 2), when the instrument and siting of the station were improved. The station belongs to a relative gravity network, spanning the Vesuvian area, periodically surveyed since 1982. It is close to an absolute gravity station established on the volcano in 1986. The absolute value of $g$ was measured in 1994, 1996, 1998 and 2003 (Berrino, 1995; Berrino, 2000).

In order to check the reliability of the gravity signals, the instrumentation is periodically calibrated and the background noise level at the station is analyzed. In fact, instrumental sensitivity can change, not always linearly, as a consequence of mechanical perturbations and the noise level at the gravity station. To characterize the background noise level, which could affect the instrumental response, the $1 \mathrm{~min}$ sampled residual gravity was analyzed to detect any 



Fig. 2a,b. Hourly values of gravity records (a), drift corrected gravity residuals (b). Anomalous record with abnormal drift and very large residuals are highlighted in circles.

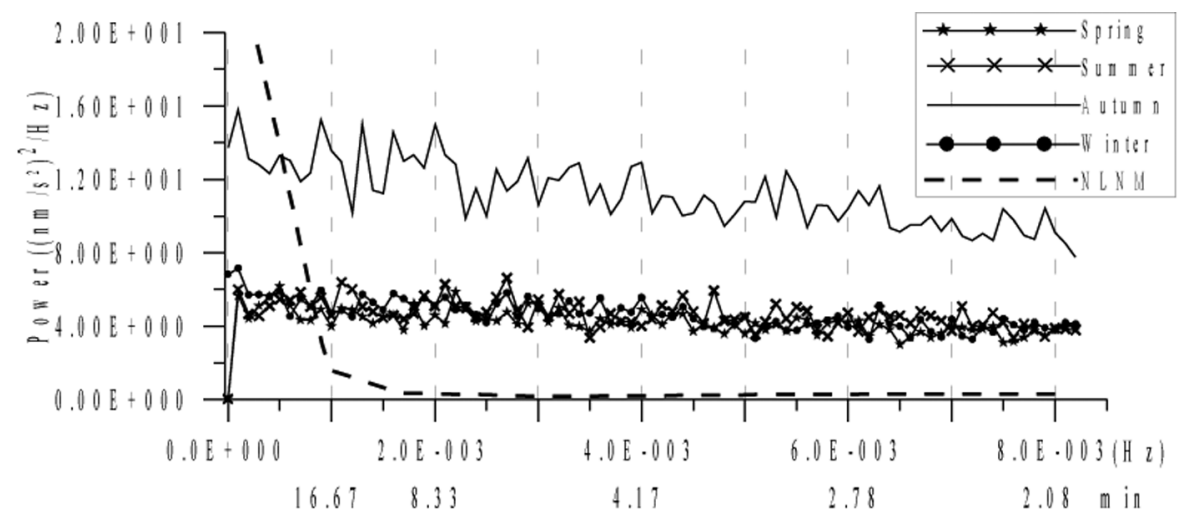

Fig. 3. Power spectra of the background noise level computed in each seasons at the Mt. Vesuvius gravity station, with the indication of the standard New Low Noise Model (NLNM) as reference.

possible seasonal dependence or the presence of spectral components which could hide or mask geophysical signals. Several time windows lasting about 1 week were selected in each season. The amplitude and spectral content of the noise (Berrino and Riccardi, 2004) show a flat trend in the analyzed spectral band (fig. 3), according to the standard New Low 
Noise Model [NLNM] (Peterson, 1993). The high noise level during the autumn is a consequence of the meteorological condition (mainly wind) at Mt. Vesuvius during that season.

Changes through time of the calibration factors for different kinds of mechanical gravimeters have been detected by several authors (e.g., Bonvalot et al., 1998; Budetta and Carbone, 1997; Riccardi et al., 2002). However, a complete understanding of the physical processes affecting the instrumental sensitivity is still far from being achieved. As changes in instrumental sensitivity can prevent the repeatability of measurements and affect the phase and ampli- tude of the recorded gravity signals, the accurate calibration of gravimeters plays a key role in high precision gravity measurements (Riccardi et al., 2002). The calibration of a gravimeter at an accuracy level of $10^{-8}$ to $10^{-9} \mathrm{~g}$, is difficult to attain because of the many problems in pursuing a known gravity change («standard») at such a level of accuracy. The stability of the calibration factors of LR-D126 has been periodically investigated on site. This kind of calibration is obtained by inducing changes in the spring length through a known «dial» turning and fitting this, by least-squares, against the instrumental output. This is the most frequently

Table I. Comparison between LR-D126 and superconducting SG-TT70-T015 meters: results (delta factor and phase) of the tidal analysis for the main tidal waves. In the last column the ratio (SG/D) of delta factors obtained by the records from the superconducting and $\mathrm{D}$ meters is listed. The tidal waves nomenclature is: O1-Diurnal lunar; P1-Diurnal lunar; K1-Diurnal luni-solar; S1-Diurnal solar; M2 Semi-diurnal lunar; S2 semi-diurnal solar.

\begin{tabular}{cccccc}
\hline \multicolumn{5}{c}{ LR-D126 } & \multicolumn{2}{c}{ SG-TT70-T015 } \\
\hline Wave & Delta & Phase $\left({ }^{\circ}\right)$ & Delta & Phase $\left(^{\circ}\right)$ & LR/SG \\
\hline O1 & $1.147 \pm 0.003$ & $-0.2 \pm 0.1$ & $1.14 \pm 0.01$ & $-0.1 \pm 0.6$ & $1.006 \pm 0.009$ \\
P1S1K1 & $1.137 \pm 0.002$ & $0.0 \pm 0.09$ & $1.130 \pm 0.009$ & $0.1 \pm 0.6$ & $1.006 \pm 0.007$ \\
M2 & $1.184 \pm 0.001$ & $1.14 \pm 0.06$ & $1.176 \pm 0.003$ & $0.9 \pm 0.2$ & $1.007 \pm 0.004$ \\
\hline
\end{tabular}

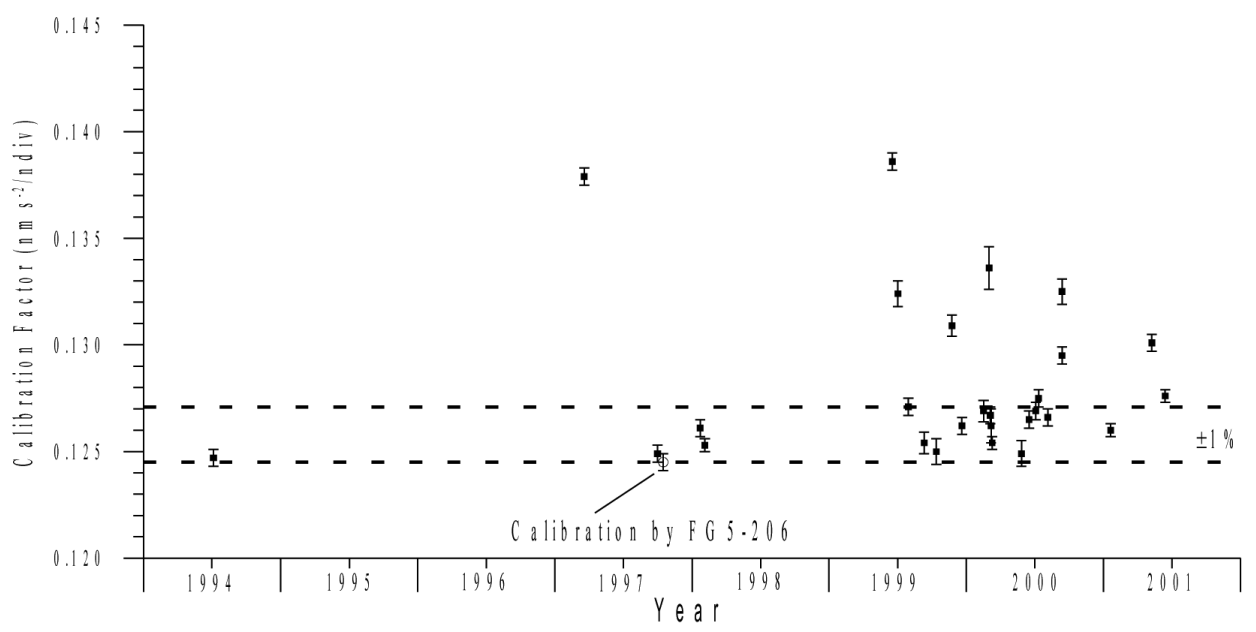

Fig. 4. Calibration factors obtained with on-site and absolute calibration for LR-D126 gravity meter; units of vertical axis (ndiv) are number of scale divisions. 




Fig. 5. On-site and theoretical calibration for LR-D126 against the occurrence of some large earthquakes $\left(M_{L}>5\right)$; «shot» on vertical axis is the arbitrary unit for the feedback frequency output.

adopted calibration procedure for continuous gravity station equipped with relative mechanical instruments. Various schemes of dial turning have been tested at Mt. Vesuvius station (Riccardi et al., 2002). Hereafter, such calibrations are referred to as «on-site» calibrations. Moreover, two additional calibrations of the feedback were carried out in June 1994 and November 1997 in Sèvres, at the Bureau International des Poids et Mesures (BIPM) during the International Comparison of Absolute Gravimeters (Becker et al., 1995, 2000). A calibration of the instrumentation was also obtained in 1997 by means of a joint intercomparison with the superconducting gravimeter SGTT70-T015 (table I) and the absolute FG5-206 gravimeter (Riccardi et al., 2002). The intercomparison between spring and superconducting gravimeters is the most suitable way to determine the transfer function of spring gravimeters in the tidal band. Detailed information on the different calibrations and operational procedures carried out at this station are given in Riccardi et al. (2002). The time distribution of the calibration factor is shown in fig. 4. In this plot the value from the intercomparison with the FG5-206 absolute gravimeter is shown and the suitable range of repeatability of the calibration factor at $1 \%$ level is also drawn. A large scattering of the calibration factor occurs from 1999 to 2001, when some anomalous signals were detected. The anomalous signals (highlighted in fig. 2a) were characterized by an abnormal drift and then very large gravity residuals.

As a consequence, the tidal analysis on the 1998-2000 data furnished a sharp decrease of the $\delta$ factors at the beginning of 1999 (Berrino and Riccardi, 2001). A theoretical value of the instrumental sensitivity was computed and compared with the calibration factors monitored «on site» to evaluate whether the calibration factor truly reflects changes in the instrumental response or is merely due to the adopted «on site» calibration procedures. The theoretical instrumental sensitivity was determined by a regression analysis between the meter's output signal and the synthetic gravity tide. Thus, a set of weekly theoretical values of calibration factor was obtained and compared with the results from the repeated calibrations (fig. 5). A good agreement between the temporal evolution of the theoretical factors and those obtained through the «on site» calibration was detected (Riccardi et al., 2002). Moreover, the set of the «on site» and theoretical calibration factors has been plotted against the time occurrence of certain large worldwide earthquakes $\left(M_{L}>5\right)$ that shook the meter strong enough to send it out of range (fig. 5). A time correlation between the larger changes of instrumental sensitivity and the occurrence of seismic events can be observed. More detailed discussion concerning the instrumental sensitivity changes on the occasion of large earthquakes is given in 
Riccardi et al. (2002) and Berrino and Riccardi (2004). They suggest a mechanical perturbation of the sensor, due to some dominant frequencies of the noise at the station on the occasion of large earthquakes. In fact the higher frequency of the seismic free oscillation excited by large earthquakes includes the fundamental mode of oscillation ( $T_{0}: 15$ to $\left.20 \mathrm{~s}\right)$ of the LaCoste and Romberg spring gravimeters (Torge, 1989). These instrumental disturbances due to large earthquakes can last several weeks.

\section{Ocean loading and atmospheric reduction}

The state of the art of the modelling of the ocean loading effect on local gravity data is hereafter reviewed and the most advanced methods in pursuing the reductions of the atmospheric effects are presented. To focus on the methodological upgrades, we present our attempt to model the barometric «local» effect on gravity data in a stable non-volcanic area by means of a barometric array. However, by the way of the methodological approaches, these results can be fruitfully applied to fix the problem of air pressure effect on local TVG in volcanic areas.
In a very general sense, Ocean Tide Loading (OTL) is the deformation of the Earth due to the weight of the ocean tides. The ocean tides induces water mass redistributions causing periodic loading of the ocean bottom. The Earth's deformation (vertical and horizontal displacement, TVG, tilt and strain) under this load is called ocean tide loading. The ocean tides as well as the body tides have more than one periodicity, so they can be described as the sum of several harmonic components having their own period. Problem areas are mostly islands and shallow seas with large tidal amplitude and fast varying phase lag. These include among the others in Europe: the Mediterranean Sea and the North Sea.

To compute the ocean tide loading the ocean tides are integrated with a weighting function $G$

$$
L(r)=\int_{A} \rho Z\left(r^{\prime}\right) G\left|r-r^{\prime}\right| d A
$$

Here $L$ is the loading phenomenon (displacement, gravity, tilt or strain) at the station located at distance $r$. The ocean tide at $r$ ' is given in its complex form $Z=A e^{i \varphi}$, where $\varphi$ is the phase; $\rho$ is the mean density of sea water and $G$ is Green's function for the distance $\left|r-r^{\prime}\right|$. The integral is taken over all global water masses $A$.

Table II. Amplitude ( $L$; in $\mathrm{nm} \mathrm{s}^{-2}$ ) and phase ( $\varphi$ in degrees) of the main harmonics of the OTL computed for Mt. Vesuvius station by means of different models.

\begin{tabular}{ccccccccccc}
\hline & \multicolumn{2}{c}{ SCW80 } & \multicolumn{2}{c}{ CSR 3.0 } & \multicolumn{2}{c}{ FES 95.2 } & \multicolumn{2}{c}{ TPXO 6.2 } & \multicolumn{2}{c}{ TPXO 7.0 } \\
\hline Wave & $L$ & $\varphi$ & $L$ & $\varphi$ & $L$ & $\varphi$ & $L$ & $\varphi$ & $L$ & $\varphi$ \\
\hline M2 & 11.5 & -85.4 & 9.2 & -68.0 & 10.6 & -69.1 & 9.5 & -67.8 & 9.6 & -66.9 \\
S2 & 4.0 & -58.8 & 3.1 & -58.6 & 4.0 & -58.1 & 4.6 & -57.7 & 3.3 & -49.6 \\
N2 & 2.3 & -100.3 & 1.7 & -82.4 & 2.2 & -84.9 & 2.1 & -66.7 & 2.2 & -80.5 \\
K2 & 1.1 & -58.9 & 0.8 & -59.1 & 1.1 & -63.4 & 0.9 & -33.9 & 1.1 & -37.6 \\
K1 & 1.1 & -131.8 & 2.0 & -84.1 & 2.8 & -76.6 & 1.5 & -83.9 & 1.5 & -81.1 \\
O1 & 1.2 & 169.0 & 1.3 & -131.7 & 2.0 & -145.3 & 1.3 & -147.4 & 1.3 & -153.0 \\
P1 & 0.4 & -136.8 & 0.7 & -90.0 & 0.9 & -84.4 & 0.6 & -100.3 & 0.4 & -121.8 \\
Q1 & 0.3 & 116.2 & 0.1 & 167.7 & 0.3 & 168.2 & 0.4 & 129.9 & 0.4 & 131.4 \\
MF & 0.4 & -16.8 & 0.5 & 27.1 & 0.5 & 27.1 & 0.4 & 33.8 & 0.3 & 32.2 \\
MM & 0.2 & -109.7 & 0.3 & 23.2 & 0.1 & 22.9 & 0.3 & 30.3 & 0.2 & 21.0 \\
SSA & 0.3 & -93.1 & 0.3 & 4.5 & 0.2 & 3.9 & 0.3 & 4.5 & 0.3 & 4.5 \\
\hline
\end{tabular}


Green's function determines how much the Earth deforms due to the point load (a general solution of this problem is given in Farrel, 1972). The next step is to replace the convolution integral by a summation. Most ocean models are given on a $0.5^{\circ}$ by $0.5^{\circ}$ grid, which justifies direct summation over these ocean grid cells if the station is more than $10 \mathrm{~km}$ from the coast. Otherwise some re-gridding is necessary. Some local solutions (models) are obtained by means of a re-gridding the model gradually towards the station.

Table II lists the amplitude $(L)$ and phase $(\varphi)$ of the main 11 harmonics of the OTL computed for Mt. Vesuvius station. These 11 harmonics are the largest in amplitude and represent most of the total tidal signal. These have been computed by means of a free OTL provider developed at the Onsala Space Observatory and maintained by M.S. Bos and H.-G. Scherneck (http://www.oso.chalmers.se/ loading/). Solutions coming from classical (SCW80) (Schwiderski, 1980) and most recent models (CSR 3.0; FES95.2, TPXO6.2, TPXO7.0) (Eanes, 1994; Le Provost et al., 1998; Egbert and Erofeeva, 2002) have been obtained. If the stations are close to the coast, like the Mt. Vesuvius one, an automatic interpolation is applied using a mask having a coastline resolution of $0.6 \mathrm{~km}$. Schwiderski's model (SCW80) is one of the oldest and it has been considered the standard for many years. It is a hydrodynamic model, given on a $1^{\circ}$ by $1^{\circ}$ grid and uses an interpolation scheme to fit the tide gauges; SCW80 model does not account for the Mediterranean sea tide. FES95.2 is an upgrade of the FES94.1 model, a pure hydrodynamic tide model tuned to fit tide gauges globally, which includes the Mediterranean Sea tide. In FES95.2 the tides in the Arctic were improved and TOPEX/Poseidon satellite altimeter data has been used to adjust the long wavelength behaviour of FES94.1. It has been calculated on a finite element grid with very fine resolution near the coast. The version used at Mt. Vesuvius station is given on a $0.5^{\circ}$ by $0.5^{\circ}$ grid. The CSR3.0 models are nothing other than a long wavelength adjustment of FES94.1 model by using TOPEX/Poseidon data and are given on a $0.5^{\circ}$ by $0.5^{\circ}$ grid. TPXO.6.2 and 7.0 have been computed using inverse theory using tide gauge and TOPEX/Poseidon data. These models have a resolution of a $0.25^{\circ}$ by $0.25^{\circ}$ grid.

The results lead to a maximum OTL effect at Mt. Vesuvius of about $10 \mathrm{~nm} / \mathrm{s}^{2}(1 \mathrm{mGal})$ with a slightly lower amplitude obtained by means of models accounting for Mediterranean Sea tides.

The amplitude and phase of such effect has to be accounted for to avoid a tidal modulation (diurnal and semi-diurnal) in the residual gravity signals.

Besides solid Earth and ocean tides, atmospheric pressure variations are one of the major sources of surface gravity perturbations preventing a highly accurate detection of small amplitude gravity signals (see e.g., Hinderer and Crossley, 2000, 2004). The continual redistribution of air mass in the Earth's atmosphere causes periodic variations in local gravity at the solar tidal frequencies as well as random variations (Warburton and Goodkind, 1977; Spratt, 1982). Gravity (measured positive down) and local atmospheric pressure correlate with an admittance of about $-3.0 \div-3.5 \mathrm{nms}^{-2} / \mathrm{hPa}$ (e.g., Warburton and Goodkind, 1977; Müller and Zürn, 1983; Merriam, 1992). Knowing that pressure changes can reach $50 \mathrm{hPa}$ in specific locations, the amplitude of atmospheric contribution to gravity may be as large as $200 \mathrm{nms}^{-2}$, which is typically only 10 times less than the solid Earth tides. Moreover, because this effect varies both in time and with frequency (Richter et al., 1995), the contribution is spread over a wide spectral domain and may inhibit the observation of small signals of non-tidal origin. The global atmosphere acts on surface gravity through two competing effects: a direct «Newtonian» attraction by air masses and an elastic contribution due to the Earth's surface loading. The amplitude and polarity of these two effects vary with distance, so the net contribution of the atmosphere coming from different distances from the gravity station is variable (e.g., Spratt 1982; Merriam, 1992; Mukai et al. 1995; Boy et al. 1998). The coherence scale of pressure fluctuations and some considerations on the hydrostatic approximation of the atmosphere, led some authors to suggest a division of the globe into «local» (within $50 \mathrm{~km}$ ), «regional» $(50$ $1000 \mathrm{~km})$ and «global» zones (>1000 km) 
(Atkinson, 1981; Merriam, 1992). In the local zone $(<50 \mathrm{~km})$ pressure can change rapidly in time, but is spatially coherent, so that pressure observations collected at the gravity site are sufficient to obtain an accurate reduction within a few tenths of $\mathrm{nm} / \mathrm{s}^{2}$ except when a front is passing through the local zone (Rabbel and Zschau, 1985). When a pressure front moves through or larger horizontal gradients affect the local zone, the band from 1 to $10 \mathrm{~km}$ from the gravity station becomes a critical area for which more detailed pressure data are needed.

Atmospheric effects on gravity are routinely reduced using a barometric admittance, which is a simple transfer function adjusted by least square fitting between pressure and gravity, both measured locally. The use of a single scalar admittance has been well established (e.g., Warburton and Goodkind, 1977; Crossley et al. 1995). When atmospheric pressure $p$ $(\mathrm{hPa})$ is recorded jointly with gravity $\mathrm{g}\left(\mathrm{nms}^{-2}\right)$ at a single station, the gravity can be reduced $\left(g_{r}\right)$ by using the relation

$$
g_{r}=g-\alpha\left(p-p_{n}\right)
$$

where $p_{n}$ is a reference pressure at the station and $\alpha$ is either a nominal value of $-3.0 \mathrm{nms}^{-2} / \mathrm{hPa}$ or determined by a least squares fit of $p$ to $g$.

The effectiveness and simplicity of this method has led to its widespread use in gravity studies for many purposes. This reduction typically accounts for some $90 \%$ of the total atmospheric effect. The drawback of this method is that the admittance shows some variation with time (e.g., Richter, 1987; Van Dam and Francis, 1998), usually on seasonal time scales, whereas the atmosphere is certainly variable on short time scales and local weather systems can move rapidly over a station in a few hours (Müller and Zürn, 1983; Rabbel and Zschau, 1985). So there is no guarantee that the correlation implied by eq. (3.2) is satisfied over all length and time scales. Furthermore Crossley et al. (2002) found that the admittance is sensitive to the time averaging windows applied on data, namely a higher admittance is found for shorter windowing. Moreover, the simple reduction using only the local pressure measurements cannot take into account either the global scale or re- gional (1000 km around the gravimeter) atmospheric effects.

Several approaches using the local pressure more effectively have been attempted, particularly with a frequency dependent admittance (e.g., Warburton and Goodkind, 1977; Crossley et al. 1995; Neumeyer, 1995; Neumeyer et al., 1998; Kroner and Jentzsch, 1998; Van Dam and Francis, 1998). The method represents a transformation of the eq. (3.2) from the time domain to the frequency $(\omega)$ domain and allowing the admittance $(\alpha)$ to be frequency dependent

$$
G_{r}(\omega)=G(\omega)-\alpha(\omega) P(\omega)
$$

Minimising $\left|G_{r}(w)\right|^{2}$ over the whole frequency range leads to

$$
\alpha(\omega)=\frac{\sum G(\omega) P(\omega)}{\sum|P(\omega)|^{2}}
$$

which is equivalent to the complex admittance defined by Warburton and Goodkind (1977). Crossley et al. (1995) demonstrated that the complex admittance, as expressed in eq. (3.4), is a powerful and versatile tool to model both local atmospheric effect and contribution due to the solar harmonics $S_{n}$ and allows to select the frequency ranges of the air pressure reduction.

\subsection{Atmospheric reduction by means of a barometric array}

Riccardi et al. (2007) investigated the efficiency of a barometric array (fig. 6) to improve the reduction of the «local» atmospheric effects on gravity data in normal weather conditions and also under extreme weather conditions. This research has been developed by using $\mathrm{Su}-$ perconducting Gravity (SG) data collected in Strasbourg and barometric records in five sites around the SG station at distances ranging between 10 and $60 \mathrm{~km}$ (fig. 6). Six months of gravity and air pressure records (fig. 7) have been analyzed both in the time and frequency domains. Some further analyses have been addressed on three time intervals (highlighted in fig. 7) characterized by large and fast air pressure changes. 




Fig. 6. Location map of the superconducting gravimeter (filled circle) and the stations of the barometric array.

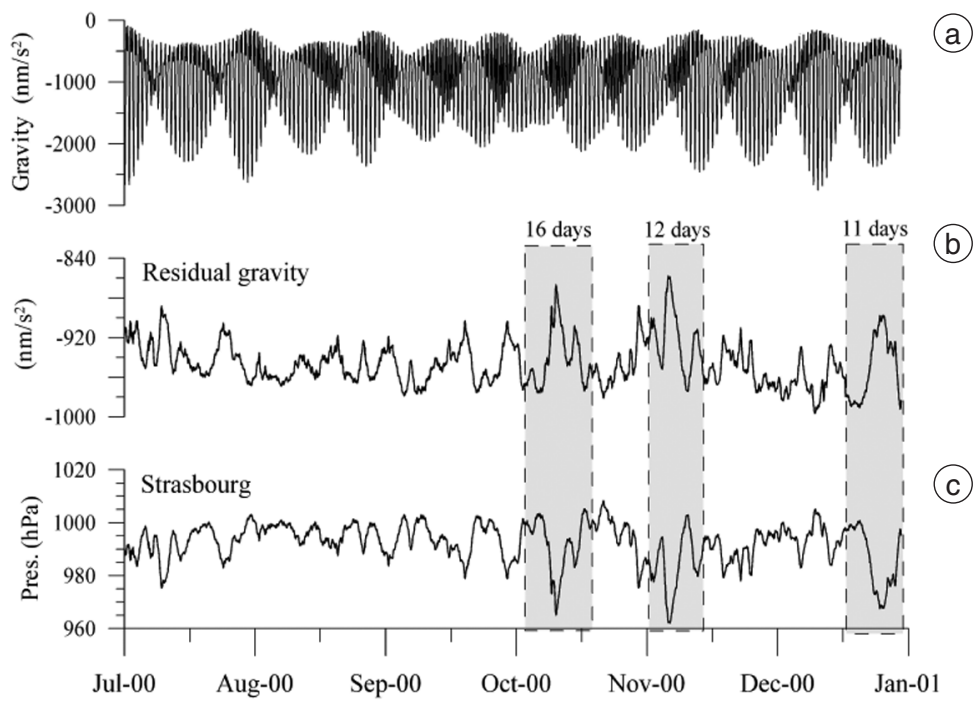

Fig. 7a-c. The Strasbourg hourly data sets: a) gravity record; b) gravity residuals; c) air pressure. The time spans highlighted in gray are characterized by large and fast pressure changes and are the target of further analyses.

Riccardi et al. (2007) used the multi-linear regression (MLR) method of Van Camp and Vauterin (2005) to express an objective signal $s_{o b j}$ (gravity residuals) as a linear combination of a set of $m$ component signals $s_{c}$ (air pressure record of each station)

$$
S_{o b j}=\sum_{m} a_{l m} S_{c m}^{n}+\mathrm{drift}+\text { residual }
$$


In this study we set $n=1$ (a linear regression). The drift term, which is used to model the longterm instrumental behaviour in the gravity record consists of a polynomial of degree $k(t$ is the time)

$$
\operatorname{drift}(a)=b_{0}+b_{1} \cdot t+b_{2} \cdot t^{2}+b_{3} \cdot t^{3}+\ldots+b_{p} \cdot t^{k}
$$

The parameters $a_{1} \ldots a_{\mathrm{n}}, b_{1} \ldots b_{\mathrm{n}}$, were estimated by least squares adjustment.
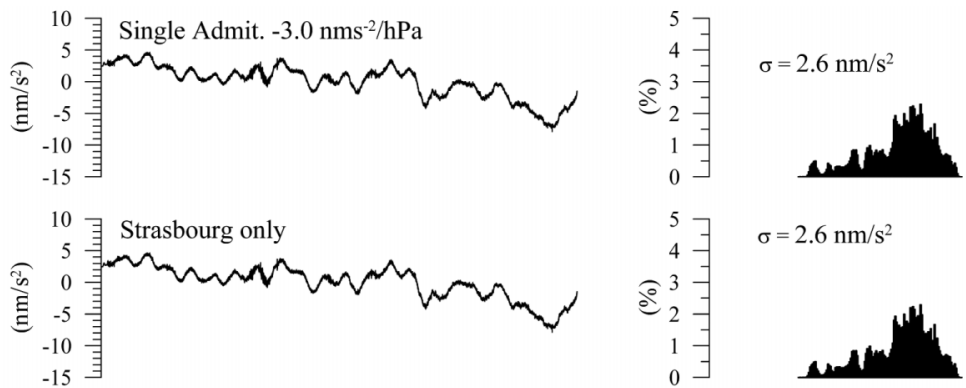

(a)

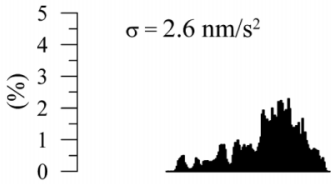

(b)


(c)


(f)

Fig. 8a-f. Residual gravity obtained for a time span 11 days long during December 2000 (ref. fig. 7a-c). Comparison of different kinds of reduction: a) by means of: a single admittance coefficient; $b$ ) a fit to pressure data from Strasbourg only; c) a fit to pressure data from the whole array; d) a frequency dependent admittance; e) air loading computed with the hybrid model; f) fourier spectrum of the reduced residual gravity. 
The MLR approach allows us to jointly account for the atmospheric effect as it can be probed trough the barometric array. A similar methodology has also been applied by Dittfeld (1995) and Kroner and Jentzsch (1998).

The results obtained on the whole data set (6 months) demonstrated that negligible improvement in the «local» atmospheric reduction derives from the use of an array, as also shown by Dittfeld (1995). Moreover the short length of our study did not permit us to investigate seasonal variations in the pressure reduction to gravity.

We further compared the efficiency of the atmospheric reduction by means of the barometric array with the one performed through global loading computation (Boy et al., 2002; Petrov and Boy, 2004). We use ECMWF (European Centre for Medium-range Weather Forecasts) surface pressure fields from the 4Dvar model as they have the highest temporal $(3 \mathrm{~h})$ and spatial $\left(0.5^{\circ}\right)$ resolution. A more detailed description of the global loading computation is given in Riccardi et al. (2007) and Petrov and Boy (2004). The results showed that gravity residuals reduced by means of the atmospheric loading using the 4Dvar surface pressure are slightly worse than those obtained by applying a single admittance coefficient. This is likely due to the low resolution of the loading model, which is unable to reconstruct high frequency local barometric changes.

These considerations could be extended when the mean atmospheric conditions are not far from the hydrostatic equilibrium. So we decided to analyze data during shorter time intervals, mainly characterized by abnormal weather conditions like when an atmospheric front is passing. Here the results for 11 days during December 2000 are shown (figs. 7 and 8).

In order to improve the time and spatial resolution of the computed global atmospheric loading, we tested a hybrid method which consists in the following steps:

- a global loading reduction using the $3 \mathrm{~h}$ and $0.5^{\circ} \times 0.5^{\circ}$ grided surface pressure fields everywhere except in the local zone. The global contribution has been recomputed from the 4Dvar model and oversampled to $60 \mathrm{~s}$ with spline interpolating functions;
- a local loading reduction obtained by dividing the local zone into a smaller grid using interpolated data and the $60 \mathrm{~s}$ pressure samples from the closest stations of the barometric array, except the central zone;

- a central zone reduction using the J9 station pressure.

All three contributions have been added leading to a hybrid time series of the atmospheric loading. The effect of the hybrid model in the load computation is clear, the increase in the model resolution has led to improve the efficiency of the global loading reduction giving results similar to those obtained through the barometric array (fig. 8c,e). To evaluate the potentiality of each aforesaid method of reduction Riccardi et al. (2007) considered the standard deviation $(\sigma)$ of the reduced gravity residuals as an estimator of the efficiency of the applied air pressure reduction. The standard deviations of gravity residuals reduced by means of the barometric array have been better than to those reduced by using an air pressure record collected in a single station. The use of the barometer array lowers the standard deviation of the gravity residuals by about $30 \%$. The improvement is essentially due to a removal of an almost quadratic background trend by using the array (see fig. 8a-c). The trend could be related to some coherent features of the barometric field at local scale sensed by the array. Moreover an improvement in the atmospheric reduction has been achieved with a frequency dependent admittance (fig. 8d); as demonstrated by several authors (Crossley et al., 1995), the reduction is significantly better mainly at high frequency ( $>2 \mathrm{cpd}$ ), because large-scale pressure fluctuations are less correlated with gravity than are local pressure fluctuations. In only one of the 3 periods of rapid changes we investigated did the array improve on standard methods, and even in that case the improvement was noticeable only in the low frequencies, but actually worse at high frequencies. The spectra of the unreduced and reduced gravity residuals according to all the reduction methods are also drawn (fig. 8f). They clearly show that a single admittance coefficient is enough to reduce the energy in all the spectral bands. Data from the barometer network improve the reduction at low frequen- 
cies $(<2.5 \mathrm{cpd})$ while at higher frequencies the results are worse. In fact, comparing the gravity residuals reduced by a single admittance coefficient with those reduced through data from the barometric array (fig. 8a,c), an increase in high-frequency ( $>3 \mathrm{cpd}$ ) noise is quite evident. These features could be due to the summation of correlated high-frequency noise in the pressure data series. Hence the use of pressure data acquired by an array to improve the gravity reduction requires special care, because they could introduce an artificial high-frequency noise. The application of the hybrid method improves the air pressure reduction in almost the entire spectral band except for the $2.0 \mathrm{cpd}$ band (fig. 8e). This would be the result of two model defaults i.e. an inefficient tidal fitting in the residual gravity computation and an inadequate modelling of the air loading due to the thermal S2 component (see Ponte and Ray, 2002).

Finally we note that during normal atmospheric conditions, when the atmosphere is in apparent hydrostatic equilibrium, the use of our local array of barometers gave no improvement over the use of the pressure at the station itself. Accounting for the geometry of the available barometric array and the typical amplitude $\left(10^{-2}\right.$ $\mathrm{hPa}$ ) of the pressure signal in the «local» zone, we could expect some improvement with a more dense array of higher quality sensors using the methods described in this paper.

A more general consideration arises from this experience: the highest level of development in air pressure reduction of local gravity data make sense only for gravity signals collected by superconducting gravimeters. Otherwise a single barometer can be enough to account for the main part of the pressure effect originating in the local zone. However it is noteworthy that a significant progress in modelling atmospheric effects, as demonstrated by several authors, can be pursued by using a frequency dependent admittance, which allows us to model the weather contribution at different frequency ranges. The reduction is significantly improved mainly at high frequency $(>2 \mathrm{cpd}$ ) and consequently the reduced gravity residuals are much smoother than the others obtained by applying different kind of reductions.

\section{Analysis of gravity record at Mt. Vesuvius and results}

This section reports the most remarkable results coming from the experience of about 15 years of gravity recording at Mt. Vesuvius (Southern Italy). The time dependent behaviour

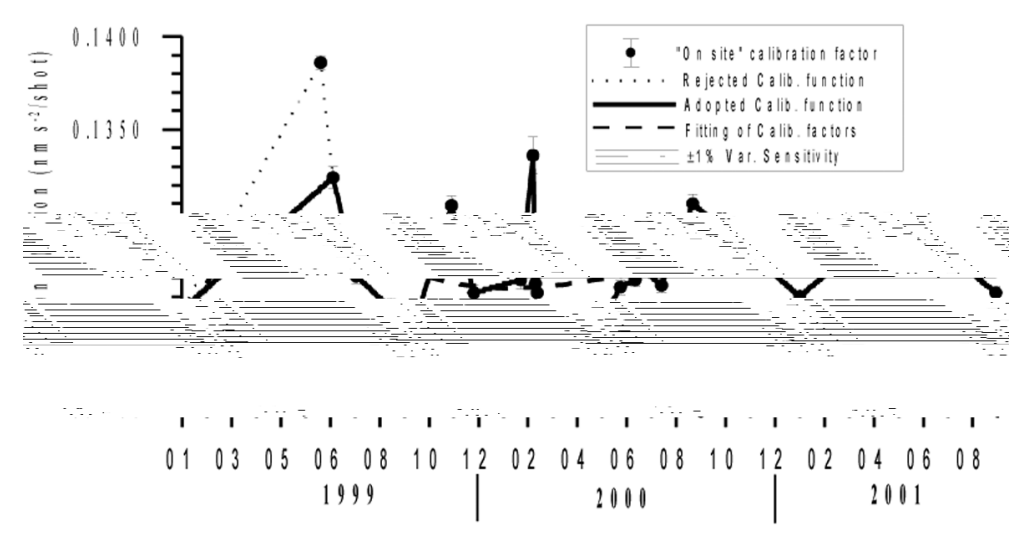

Fig. 9. Calibration functions (dotted and continuous lines) interpolating the factors obtained with the on-site calibrations (points with error bars) and polynomial fitting (dashed line). The thickest line is the calibration function adopted to convert gravity records in $\mathrm{nm} / \mathrm{s}^{2}$. 
of the tidal gravimetric factors is compared with the results from relative and absolute gravity surveys and seismic activity. The results are interpreted in the framework of the present-day dynamics of Mt. Vesuvius.

To reduce the instrumental effect on tidal parameters ( $\delta$ factors and phases) computed at Mt. Vesvius gravity station, a calibration function has been computed to convert the recorded signal into $\mathrm{nm} / \mathrm{s}^{2}$ (fig. 9); this function derives from the available data-set of the calibration factors periodically checked at the gravity station. In detail, two calibration functions have been computed respectively by including or excluding the highest outlier of the calibration factors data-set obtained in 1999.

The harmonic tidal analyses were repeated on the gravity record calibrated by means of the two functions to rule out any dependence of $\delta$ factors and phases from instrumental effects, namely the temporal changes of the calibration factors. Thus, taking into account these results, the first calibration function (dotted line in fig. 9) was rejected and we adopted the second function (bold continuous line in fig. 9) to calibrate the gravity record (fig. 2) spanning 19992001 interval.

All of the gravity records were analysed to obtain tidal parameters and gravity residuals (fig. 2). The latter have been computed by subtracting the luni-solar effect (body tide), according to Tamura's gravity potential catalogue (Tamura, 1987) from the gravity record, as well as a first order correction for the atmospheric effect and instrumental drift. The mean coefficient, $-3.5 \mathrm{nms}^{-2} / \mathrm{hPa}$, has been adopted to reduce the atmospheric effect in gravity record (Berrino et al., 1997, 2000). The Wahr-Dehant-
Zschau (WDZ) Earth model (Wahr, 1981; Dehant, 1987; Zschau and Wang, 1987) has been adopted to compute tidal parameters, while for the computation of gravity residuals a synthetic tide was calculated using tidal parameters computed from the local gravity records since 1994. As regards the reduction of the drift, accurate modelling is necessary to remove the instrumental drift and to distinguish it from longterm gravity changes due to volcanic sources. This is mainly required in quiescent volcanic areas, where «slow» and small temporal gravity changes are expected. Otherwise in the case of large short-lasting (few hours or days) gravity variations, as observed in open-conduit volcanoes (Carbone et al., 2006), the instrumental drift can be easily modelled.

Here, drift has been constrained by taking into account the temporal gravity changes obtained by both relative and absolute measurements periodically performed at Mt. Vesuvius. The latter show a negligible contribution on the trend observable in fig. $2 \mathrm{~b}$; thus, the long term component of the gravity record can be considered instrumental drift. The drift corrected gravity residuals are shown in fig. $2 b$.

The data set has been analysed by means of an algorithm for tidal analysis: «ETERNA 3.3» (Wenzel, 1996). The results for the main tidal waves are summarized in table III. The analyses have been performed on the gravity record rearranged in some temporal subsets to check the time stability of the solutions and investigate the temporal changes of $\delta$ factors with a better resolution. The results of these tidal analyses have also been compared with the previous ones from 1987-1991 and the 1960 (table III, fig. 10c).

Table III. Comparison among tidal gravimetric factors determined during the 1960s, 1987-91 and 1994-2000 (for tidal waves nomenclature refer to table I).

\begin{tabular}{cccccc}
\hline \hline $\begin{array}{c}\text { Wave } \\
\text { Imbò } \text { et al. (1965a) }\end{array}$ & $\begin{array}{c}1959-1961 \\
\text { Imbò } \text { et al. }(1965 \mathrm{a})\end{array}$ & $\begin{array}{c}1961-1965 \\
\text { Berrino } \text { et al. (1993b) }\end{array}$ & $1987-1991$ & $1994-1998$ & $1999-2000$ \\
\hline O1 & 1.156 & 1.038 & $1.08 \pm 0.02$ & $1.126 \pm 0.002$ & $1.143 \pm 0.004$ \\
K1 & P1S1K1:0.928 & 1.083 & $1.05 \pm 0.01$ & $1.117 \pm 0.001$ & $1.123 \mathrm{v} 0.003$ \\
M2 & 1.154 & 1.068 & $1.11 \pm 0.01$ & $1.1488 \pm 0.0007$ & $1.155 \pm 0.001$ \\
S2 & 1.147 & 1.107 & $1.03 \pm 0.02$ & $1.144 \pm 0.004$ & $1.155 \pm 0.003$ \\
\hline
\end{tabular}



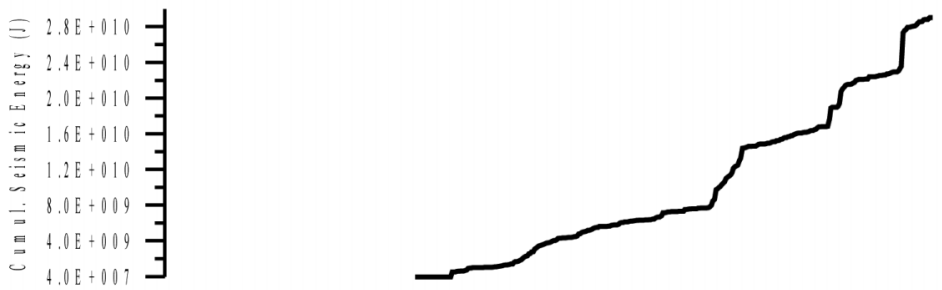

(a)
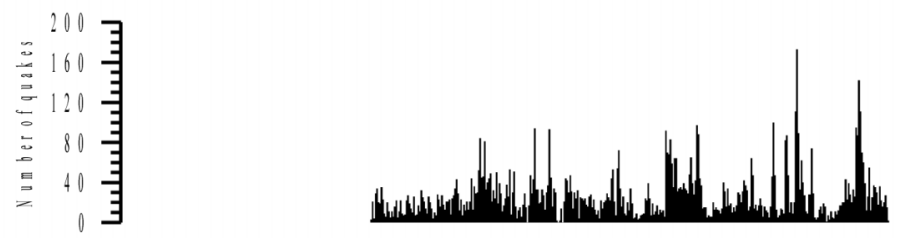

(b)
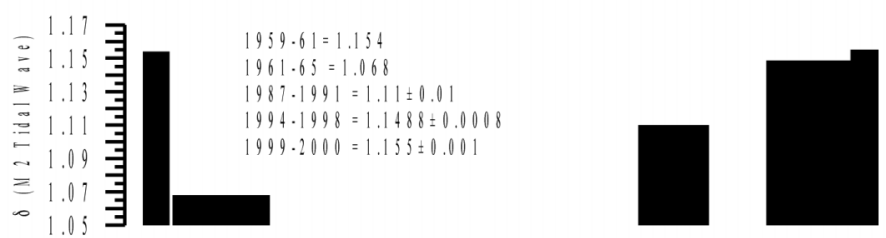

(c)

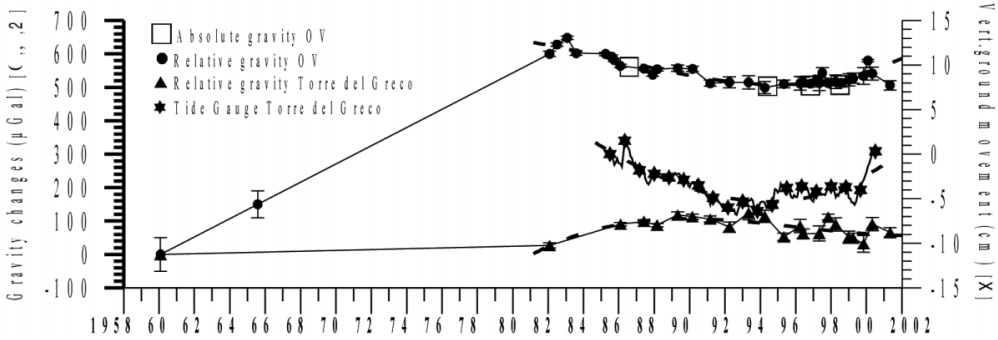

(d)

Fig. 10a-d. Time behaviour of Vesuvius dynamics from 1959 to 2001: a-b) seismic activity; c) tidal gravity factor for $M_{2}$ tidal wave; d) gravity changes $(\mu \mathrm{Gal})$ at the Osservatorio Vesuviano station plus gravity and elevation changes at Torre del Greco.

Although a calibration function has been adopted, aimed at eliminating or at least reducing the instrumental effects, the results of the tidal analyses (table III) show an increase in the $\delta$ factor in the period 1999-2000. Anyway the assumption of a calibration function and all the efforts aimed at achieve a rigorous calibration of the LCR D126 do not rule out bona fide some instrumental effects on the observed delta temporal changes at Mt. Vesuvius gravity station.

It is noteworthy that these variations are well correlated with some changes in the activ- ity of Mt. Vesuvius. In fact a seismic crisis began in October 1999 (Iannaccone et al., 2001) and a significant inversion of the trend of the gravity changes occurred in 1994 as deduced by both relative and absolute measurements.

In order to better understand the relationship, if any, between the results of tidal analyses and volcano dynamics, $\delta$ factor and gravity changes have been reconstructed by the available data for the last forty years and interpreted in the context of the activity of Mt. Vesuvius (fig. 10a-c). 
Figure 10d shows the observed TVG at the Osservatorio Vesuviano station. The reliability of this gravity change may be strongly constrained by taking into account data from others stations of the Mt. Vesuvius relative gravity network. As an example, fig. 10d shows the gravity changes at Torre del Greco, about $5 \mathrm{~km} \mathrm{SW}$ of the Mt. Vesuvius crater, and the vertical ground movement continuously obtained by tide gauge data. Tide gauge data were collected very close to the Torre del Greco gravity station. An inversion of the trend, detected in 1993-1994, is also evident in the ground movement. A high degree of similarity in the changes observed at both stations is clear.

The results of these tidal analyses have also been compared with the previous ones from 1987-1991 and the 1960s (table III, fig. 10c). An increasing trend from 1961 to the present in the amplitude of the tidal waves is clearly detectable. Taking into account the logistic and instrumental differences between the 1959-1965 (Askania meter Gs9, Gs11) and 1987-2001 recording stations, a rough comparison among the different data can be made. From 19611965 to 1987-1991, changes in the tidal parameters cannot be considered significant, while an increase can be noted from 1991 to 1994 and, as previously discussed, in 1999-2000. The latter shows tidal parameters similar to the values determined in the 1959-61 time interval.

It is noteworthy that the main changes in tidal parameters again seem well correlated with the temporal behaviour of the activity of Mt. Vesuvius (Berrino et al., 2006). At least three crises (1989-1991, 1996, 1999-2000) (figs. 10a-b) are reported (Berrino et al., 1993a; Vilardo et al., 1996; Iannaccone et al., 2001). Moreover, an increase in seismicity was also well documented in 1963-1964 (Imbò et al., 1965b). Concerning gravity changes, here we focus on the results of the episodic gravity measurements since 1982 collected on Mt. Vesuvius relative gravity network (Berrino, 2000; Berrino and Riccardi, 2000). The observed temporal gravity change at the Osservatorio Vesuviano station (fig. 10d) shows an increase (more then $20 \mu \mathrm{Gal} /$ year) in the 19591983 time interval (Berrino and Riccardi, 2000; 2001), as inferred by reviewing data collected during 1959-1960 (Tribalto and Maino, 1962) and 1965 (Bonasia, unpublished data) gravity surveys. This trend fits the gravity data collected during the 1980s, when a continuous gravity increase affected the whole area (Berrino, 2000).

Focusing on the most recent data (fig. 10), it is interesting to note that the increase of the $\mathrm{d}$ factor from 1991 to 1994 (fig. 10c) occurred during or soon after the 1989-91 seismic crisis. A gravity decrease of about $60 \mu \mathrm{Gal}$ (fig. 10d) (Berrino et al., 1993a) was also detected between 1989 and 1991 at the Osservatorio Vesuviano gravity station by both relative and absolute gravity measurements.

The tidal response of the investigated area could indicate a variation in the deformational behaviour probably due to the change in the mean mechanical properties of Mt. Vesuvius, as already suggested by Berrino et al. (1997).

Up to now any additional information on volcanic sources may be inferred by the gravity residuals. Although their time distribution clearly shows an increase in amplitude and scattering during 1998-2001, coinciding with the increasing seismicity, there are not enough clear gravity signals to detect or hypothesize the presence of volcanic input.

\section{Conclusions}

The above described results show how the continuous gravity record on active volcanoes could be a useful investigative tool to detect volcanic inputs, but much care must be taken to remove from the recorded signals the effects due to the instrumental response and non-volcanic sources. As changes in instrument sensitivity can reduce the repeatability of measurements and affect the phase and amplitude of recorded gravity signals, the accurate calibration of gravimeters in high-precision gravimetry is topical. The stability of the calibration factors has to be deeply investigated through different calibration methods (e.g., inter-comparison with $\mathrm{AG}$ and $\mathrm{SG}$ ).

Concerning the modelling of the non-volcanic contribution to TVG, currently the tide generating potential is at a suitable level of ac- 
curacy $\left(1 \mathrm{~nm} / \mathrm{s}^{2}\right)$, so highly accurate catalogues of tide potential are available. Even the OTL modelling is highly accurate. The TOPEX/Poseidon satellite altimeter data deeply improved the studies on the OTL effects. Nevertheless some local solutions are needed for instance for volcanic islands.

Moreover the state of the art demonstrates that the gravity record could be able to characterize the deformational behaviour of the volcano through the time evolution of the $\delta$ factor. However, as mentioned by several authors (e.g., Arnoso et al., 2001; Robinson, 1991; Melchior, 1995), this points out the existing necessity of theoretical studies and observations of the highest quality to answer the different questions regarding the significance of the tidal gravity anomaly and how it relates to mechanical properties of the upper crust. On the other hand, the capability of gravity residuals at least in the volcanic area characterized by a low level dynamics, requires a significant improvement in modelling mainly instrumental drift. However, the joint application of relative, absolute and continuous gravimetry is strongly recommended, to better remove the longterm instrumental drift. Thus the recognition of real gravity changes from apparent ones, due to instrumental behaviour, becomes more reliable. Currently, no additional information on volcanic sources may be inferred from the gravity residuals at Mt. Vesuvius permanent station. An improvement in the study of the mass redistribution due to volcanic processes by means of gravity residuals could derive from the use of at least a reference station outside the volcano, which would make it possible to model and exclude long-term and non-volcanic «regional» effects (Berrino et al., 1997).

In quiescent volcanic areas, undertaken by «slow» and small temporal gravity changes, it is hard to recover signals (residual gravity) related to volcanic activity by means of mechanical gravimeters. This is mainly due to the strong and non-linear instrumental drift affecting the signals acquired by such sensors. The availability of SGs in active volcanic areas is hoped for because of their very small instrumental drift, high and stable sensitivity. SGs would allow to detect very slow and small TVGs often related with re-filling process of magma chamber.

The reduction of the air pressure effects on local gravity through the most advanced methods, such as global loading computation or array application, is redundant for TVG collected by means of mechanical gravimeters.

\section{Acknowledgements}

The authors are very grateful to J.-P. Boy from EOST for the computation of the global loading air pressure effect on local gravity. The authors are deeply indebted to the anonymous referee who greatly improved the paper with his/her comments and suggestions. For the final form of this manuscript the comments of D. Carbone have also been considered. The authors thank C. Del Negro from INGV for his editorial work.

\section{REFERENCES}

ARnOSO, J., J. FERnANDEZ and R. VIEIRA (2001): Interpretation of tidal gravity anomalies in Lanzarote, Canary Islands, J. Geodyn., 31, 341-354.

Atkinson, B. W. (1981): Meso-Scale Atmospheric Circulations (Academic Press, London), pp. 495.

Becker, M., L. Balestri , L. Bartell, G. Berrino, S. BonVAlot, G. CSAPò, M. Diament, V. D'ERrico, C. GAGNON, C. Gerstenecker, P. ,Jousset, A. Kopaev, J. Liard, I. Marson, B. Meures, I. NowaK, S. NaKai, F. Rehren, B. Richter, M. Schnüll, A. Somerhausen, W. Spita, G. SzATMARI, M. van RuYMBEKE,H-G. WenZel, H. WILMES, M. ZUCCHI and W. ZÜRN (1995): Microgravimetric measurements at the 1994 international comparison of absolute gravimeters, Metrologia, 32, 145-152.

Becker, M., G. Berrino, A.G. Camacho, R. Falk, O. Francis, J.E. Friederich, C. Gagnon, C. GersteNECKer, G. LÄUfer, J. Liard, B. Meures, F.-J. NAVARRO, I. NOWAK, F. REHREN, U. RiCCARDI, B. RiCHTER, M. Schnüll, D. StizZa, M. van RuYmbeke, P. VAuterin and H. WILMES (2000): Results of relative gravimeter measurements at the ICAG97 intercomparison, Bureau Gravim. Int. Bull. Inf., 85, 61-72.

BERRINO, G. (1995): Absolute gravimetry and gradiometry on active volcanoes of Southern Italy, Boll. Geofis. Teor. Appl., 37 (146), 131-144.

BERRINO, G. (2000): Combined gravimetry in the observation of volcanic processes in Southern Italy, J. Geodynamics, 30, 371-388.

BERRINO, G. and U. RICCARDI (2000): Non-statyonary components of the gravity field at Mt. Vesuvius (Southern Italy): correlations with different aspects of its present-day dynamics, Comptes Rendus of 88th Journées Luxembourgeoises de Géodynamique (JLG), Munsbach 32-37. 
Berrino, G. and U. RicCARdi (2001): Gravity tide at Mt. Vesuvius (Southern Italy): correlations with different geophysical data and volcanological implications, $J$. Geod. Soc. Japan, 47 (1), 121-127.

BERRINO, G. and U. RICCARDI (2004): Far-field gravity and tilt signals by large earthquakes: real or instrumental effects?, Pure Appl. Geophys., 161, 1379-1397. dyn., 30, 371-388.

Berrino, G., U. Coppa, G. De Natale and F. Pingue (1993a): Recent geophysical investigation at SommaVesuvius volcanic complex, J. Volcanol. Geotherm. Res., 53, 11-26.

Berrino, G., G. Corrado, R. Magliulo and U. Riccardi (1997): Continuous record of the gravity changes at Mt. Vesuvius, Ann. Geofis., 40 (5), 1019-1028.

Berrino, G., G. Corrado, R. Magliulo and U. Riccardi (2000): Continuous gravity record at Mount Vesuvius: a tool to monitor its dynamics, Phys. Chem. Earth A, 25 (9-11), 713-717.

Berrino, G., G. Corrado, U. RicCARdi (2006): On the capability of recording gravity stations to detect signals coming from volcanic activity: The case of Vesuvius, $J$. Volcanol. Geotherm. Res., 150, 270-282.

Berrino, G., B. Ducarme and R. Magliulo (1993b): Gravity tide and volcanic activity in Southern Italy, in Proceedings of the XII National Meeting Gruppo Nazionale Geofisica della Terra Solida, 997-1001.

Bonvalot, S., M. Diament and G. Gabalda (1998): Continuous gravity recording with Scintrex CG-3M meters: a promising tool for monitoring active zones, Geophys. J. Int., 135, 470-494.

Boy, J.-P., P. GEGOUT and J. HindERER (2002): Reduction of surface gravity data from global atmospheric pressure loading, Geophys. J. Int., 149, 534-545.

Boy, J.-P., J. Hinderer and P. GEGOUT (1998): Global atmospheric pressure loading and gravity, Phys. Earth Planet. Int., 109, 161-177.

Budetta, G. and D. CARbone (1997): Potential application of the Scintrex CG-3M gravimeter for monitoring volcanic activity: results of field trials on Mt. Etna, Sicily, J. Volcanol. Geotherm. Res., 76, 199-214.

Carbone, D., G. Budetta, F. Greco and H. Rymer (2003): Combined discrete and continuous gravity observations at Mt. Etna, J. Volcanol. Geotherm. Res., 123, 123-135.

Carbone, D., L. Zuccarello, G. Saccorotti and F. GreCO (2006): Analysis of simultaneous gravity and tremor anomalies observed during the 2002-2003 Etna eruption, Earth Planet. Sci. Lett., 245, 616-629.

Chao, B.F. (1994): The geoid and Earth rotation, in Geophysical Interpretations of Geoid, edited by P. VANICEK and N. Christou ( CRC Press, Boca Raton), 285-298.

Crossley, D. and J. Hinderer (1995): Global Geodynamics Project - GGP, Cahiers du Centre Europeen de Géodynamique et de Séismologie, 11, 244-271.

Crossley, D.J., O.G. Jensen and J. Hinderer (1995): Effective barometric admittance and gravity residuals, Phys. Earth Planet. Int., 90, 221-241.

Crossley, D.J., J. Hinderer and S. Rosat (2002): Using atmosphere-gravity correlation to derive a time-dependent admittance, Bull. Inf. Marées Terrestres, 136, 10809-10820.

DAVIS, P.M. (1981): Gravity and Earth tides measured on an active volcano, Mt Etna, Sicily, J. Volcanol. Geotherm.
Res., 11, 213-223.

Dehant, V. (1987): Tidal parameters for an inelastic Earth, Phys. Earth Planet. Int., 49, 97-116.

DitTFELD, H.-J. (1995): Non-tidal features in the SG-record at Potsdam, Cahiers du Centre Européen de Géodynamique et de Séismologie, 11, 79-88.

EANES, R.J. (1994): Diurnal and semidiurnal tides from TOPEX/POSEIDON altimetry, Eos, 75, 108.

EgBert, G.D. and L. EROFEEvA (2002): Efficient inverse modeling of barotropic ocean tides, J. Atmos. Oceanic Technol., 19, 183-204.

FARRELL, W. E. (1972): Deformation of the Earth by Surface Loads, Rev. Geophys. Space Phys., 10 (3), 761-797.

GoodKInd, J.M. and C. Young (1991): Gravity and hydrology at Kilauea volcano, the Geysers and Miami, Cahiers du Centre Européen de Géodynamique et de Séismologie, 3, 163-167.

Hinderer, J. and D. Crossley (2000): Time variations and inferences on the Earth's structure and dynamics, Surv. Geophys., 21, 1-45.

Hinderer, J. and D. Crossley (2004): Scientific achievements from the first phase (1997-2003) of the Global Geodynamics Project using a worldwide network of superconducting gravimeters, J. Geodyn., 38, 237-262.

iannaccone, G., G. Alessio, G. Borriello, P. Cusano, S. Petrosino, P. Ricciolino, G. Talarico and V. TorelLO (2001): Characteristics of the seismicity of Vesuvius and Campi Flegrei during the year 2000, Ann. Geofis., 44 (5-6), 1075-1091.

Imbò, G., V. BonAsia and A. Lo BAscio (1964): Marea gravimetrica all'Osservatorio Vesuviano, Ann. Osservatorio Vesuviano, 5 (S6), 161-184.

IMBò, G., V. BonASIA and A. Lo BAscio (1965a): Variazioni della marea della crosta all'Osservatorio Vesuviano. Ann. Osservatorio Vesuviano, 7 (S6), 181-198.

Imbò, G., L. Casertano and V. Bonasia (1965b): Considerazioni sismo-gravimetriche sulle manifestazioni vesuviane del Maggio 1964, in Proceedings of the XIV Convegno nazionale Associazione Geofisica Italiana, 291-300.

Kroner, C. and G. Jentzsch (1998): Comparison of air pressure reducing methods and discussion of other influences on gravity, in Proceedings of the 13th Earth Tide Symposium, Brussels, 423-430,.

Le Provost, C., F. Lyard, J.M. Molines, M.L. Genco and F. RaBilloud (1998): A hydrodynamic ocean tide model improved by assimilating a satellite altimeterderived data set, J. Geophys. Res., 103 (C3), 55135529.

Melchior, P. (1995): A continuing discussion about the correlation of tidal gravity anomalies and heat flow densities, Phys. Earth Planet. Int., 88, 223-256.

Melchior, P. and B. DuCARME (1991): Tidal gravity anomalies and tectonics, in Proceedings of the 11th Inter. Symp. Earth Tides, Helsinki, edited by J. KAKKURI, 445-454.

Merriam, J. B. (1992): Atmospheric pressure and gravity, Geophys. J. Int., 109, 488-500.

Mukai, A., T. Higashi, S. Takemoto, I. Nakagawa and I. NAITO (1995): Accurate estimation of atmospheric effects on gravity observations made with a superconducting gravity meter at Kyoto, Phys. Earth Planet. Int., 91, 149-159. 
MÜLLER, T. and W. ZÜRN (1983): Observation of the gravity changes during the passage of cold fronts, J. Geophys., 53, 155-162.

NEUMEYER, J. (1995): Frequency dependent atmospheric pressure corrections on gravity variations by means of cross spectral analysis, Bull. Inf. Marées Terrestres, 122, 9212-9220.

Neumeyer, J., F. Barthelmes and D. Wolf (1998): Atmospheric pressure correction for gravity data using different methods, in Proceedings of the 13th Earth Tide Symposium, Brussels, 431-438,

Peterson, J. (1993): Observations and modelling of seismic background noise, Open File Report 93-322 (U.S. Department of Interior Geological Survey, Albuquerque, New Mexico).

Petrov, L. and J.-P. Boy (2004): Study of the atmospheric pressure loading signal in VLBI observations, J. Geophys. Res., 109, B03405, 10.1029/2003JB002500.

PONTE, R.M. and R.D. RAY (2002): Atmospheric pressure corrections in geodesy and oceanography: a strategy for handling air tides, Geophys. Res. Lett., 29, 2153, doi: 10.1029/2002GL016340.

RABbel, W. and J. Zschau (1985): Static deformations and gravity changes at the Earth's surface due to atmospheric loading, J. Geophys., 56, 81-99.

Riccardi, U., G. Berrino and G. Corrado (2002): Changes in the instrumental sensitivity for same feedback equipping LaCoste and Romberg gravity meters, Metrologia, 39, 509-515.

RiCCARDI, U., J. HINDERER and J.-P. BoY (2007): On the efficiency of barometric arrays to improve the corrections of atmospheric effects on gravity data, Phys. Earth Planet. Int., 161, 224-242.

Richter, B. (1987): Das supraleitende Gravimeter, Ph.D. Thesis (Deutsche Geodät. Komm., C 329, Frankfurt am Main), pp. 124.

Richter, B., H.G. WenZel, W. ZÜrn and F. KlopPing (1995): From Chandler wobble to free oscillations: comparison of cryogenic and other instruments in a wide period range, Phys. Earth Planet. Int., 91, 131-148.

RoBinson, E.S. (1989): Tidal gravity, heat flow, and the upper crust, Phys. Earth Planet. Int., 56, 181-185.

Robinson, E.S. (1991): Correlation of tidal gravity and heat flow in eastern North America, Phys. Earth Planet. Int., 67, 231-236.

SCHWIDERSKI, E.W. (1980): On charting global ocean tides. Rev. Geophys. Space. Physics., 18 (1), 243-268.
SPRATT, R.S. (1982): Modelling the effect of atmospheric pressure variations on gravity, Geophys. J.R. Astron. Soc., 71, 173-186.

TAMURA, Y. (1987): A harmonic development of the tidegenerating potential, Bull. Inf. Marées Terrestres, 99, 6813-6855.

Torge, W. (1989): Gravimetry (de Gruyter, Berlin, New York), pp. 465.

Tribalto, G. and A. MAINo (1962): Rilevamento gravimetrico della zona circumvesuviana, Ann. Osservatorio Vesuviano, 6 (S4), 134-172.

VAN CAMP, M. and P. VAUTERIN (2005): Tsoft: graphical and interactive software for the analysis of time series and Earth tides, Comput. Geosci., 31 (5), 631-640.

VAN DAM, T. and O. Francis (1998): Two years of continuous gravity measurements of tidal and non-tidal variations of gravity in Boulder, Colorado, Geophys. Res. Lett., 25, 393-396.

VAN RUYMBEKE, M. (1991): New Feedback Electronics for LaCoste \& Romberg Gravimeters, Cahiers du Centre Européen de Géodynamique et de Séismologie, 4, 333-337.

van Ruymbeke, M., R. Vieira, N. D'Oreye, A. SomerHAUSEN and N. Grammatika (1995): Technological Approach from Walferdange to Lanzarote: the EDAS Concept, in Proceeding 12th Int. Symp. on Earth tides, (Science press, Beijing, China), 53-62.

Vieira, R., M. van RuymbeKe, J. Fernandez, J. Arnoso and C. DE TORO (1991): The Lanzarote underground laboratory, Cahiers du Centre Européen de Géodynamique et de Séismologie, 4, 71-86.

Vilardo, G., G. De Natale, G. Milano and U. Coppa (1996): The seismicity of Mt. Vesuvius, Tectonophysics, 261, 127-138.

WAHR, J.M. (1981): Body tides on an elliptical, rotating, elastic and oceanless Earth, Geophys. J. R. Astr. Soc., 64, 677-703.

WARBURTON, R.J. and J.M. GoOdKIND (1977): The influence of barometric-pressure variations on gravity, Geophys. J. R. Astr. Soc., 48, 281-292.

WENZEL, H.G. (1996): The nanoGal software: Earth tide data processing package ETERNA 3.30, Bull. Inf. Marées Terrestres, Bruxelles, 9425-9438.

ZschAU, J. and R. WANG (1987): Imperfect elasticity in the Earth's mantle. Implication for Earth tides and long period deformation, in Proceedings of the 9th International Symposium on Earth Tides, New York, 605-629. 